\title{
A Compact Low-Pass Filter with Simple Structure and Sharp Roll-Off
}

\author{
Mohammad (Behdad) Jamshidi \\ Department of Electromechanical Engineering and \\ Power Electronics (KEV), \\ University of West Bohemia \\ Pilsen, the Czech Republic \\ jamshidi@kev.zcu.cz \\ Saeed Roshani* \\ Department of Electrical Engineering, Kermanshah \\ Branch, Islamic Azad University, Kermanshah, Iran \\ s roshany@yahoo.com \\ *Corresponding Author
}

\author{
Sobhan Roshani \\ Department of Electrical Engineering, Kermanshah \\ Branch, Islamic Azad University, Kermanshah, Iran \\ sobhan_roshany@yahoo.ca \\ Jakub Talla \\ Department of Electromechanical Engineering and \\ Power Electronics (KEV), \\ University of West Bohemia \\ Pilsen, the Czech Republic \\ talic@rice.zcu.cz
}

\begin{abstract}
In this paper a compact low pass filter (LPF) with desirable figure of merit (FOM) and sharp roll-off is designed. The cut-off frequency of the designed filter is $3 \mathrm{GHz}$. The designed filter has a sharp transition-band of $0.88 \mathrm{GHz}$, from 3 to $3.88 \mathrm{GHz}$ with corresponding attenuation levels of -3 and $-60 \mathrm{~dB}$, respectively. Also, the proposed filter has wide ultra stop-band from $3.8 \mathrm{GHz}$ to $10 \mathrm{GHz}$ with $20 \mathrm{~dB}$ suppression level. The dimensions of the proposed LPF is $0.13 \lambda \mathrm{g} \times 0.058 \lambda \mathrm{g}$, which shows excellent size reduction.
\end{abstract}

Keywords-component; low pass filter ; microstrip line; size reduction; wide stop-band

\section{INTRODUCTION}

Recently, microstrip filters are widely used in wireless circuits and systems [1-5]. Among the microstrip filters, compact LPFs with high performance are more attractive [1]. Several methods have been presented to achieve desirable mentioned parameters in LPFs. For instance, defected ground structure (DGS) and electromagnetic bandgap (EBG) techniques are used in [6-12] to design the LPF. However, these methods need backside etching and complex fabrication procedures.

Designing of the LPF is mainly performed by designing of the resonators. So far, several resonators have been presented for designing of the LPFS. For instance, triangular [1], rectangular [1] curved [2], T-shaped [11], $\pi$-shaped [13] resonators, stepped impedances [14] and open stubs [15] have been widely used to design different types of LPFs.

Despite of providing stop-band, resonators can also decrease the circuit size. For instance, curved Tshaped and $\pi$-shaped resonators can decrease the overall size of the filter $[2,11]$. Usually a suppressor cell is inserted in the LPF structure to provide wide stop-band. Resonators can produce transmission zeros
(TZs) at desired frequencies. In [1] triangular and rectangular resonators are used to create an LPF with sharp roll-off and wide stop-band. Twelve Tshaped structures are used in [11] to design an aperiodic LPF at $700 \mathrm{MHz}$. This twelve section structures can provide twelve TZs which lead to a wide stop-band. This aperiodic LPF is finally used to design a harmonic suppressed power divider. A common application of LPFs is to use them in harmonic suppressed power dividers [16-18].

Compact LPFs with sharp response and wide harmonics suppression can be widely used in amplifiers design [19-20] and satellite communication systems [21].

In this design, open stubs, tapered and triangular resonators are applied to create a small LPF with good parameters.

\section{DESIGN OF THE LPF}

To design the desired LPF at first a main resonator should be designed. A double trapezoidal cells are applied as the main resonator for the proposed circuit. The layout structure of this main resonator is depicted in Fig. 1 (a), while the scattering parameters of the main resonator are illustrated in Fig. 1(b).

All of the simulated results of the proposed LPF are obtained by electromagnetic simulator advanced design system (ADS) software.

The scattering parameters describe the electrical behavior of a linear device, which can be defined by a matrix. For a two port filter scattering parameters can be written in a $2 \times 2$ matrix. The $S_{21}=S_{12}$ parameters show the insertion loss of the filter, while the $S_{11}=S_{22}$ parameters show the return loss of the filter.

According to Fig. 1(b), the designed main resonator provides a $\mathrm{TZ}$ near $4.6 \mathrm{GHz}$ and also provides a suppression band near $3 \mathrm{GHz}$ up to 10 GHz. 
Figure 1. The (a) layout and (b) simulated S-parameters of the main resonator.

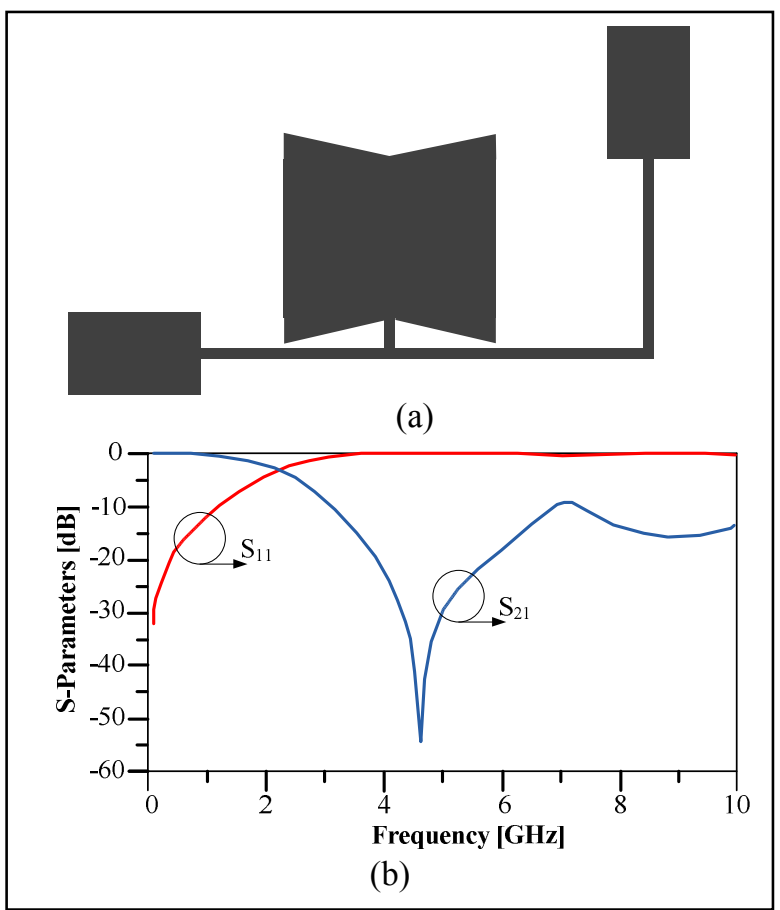

Frequency of the obtained $\mathrm{TZ}$ can be tuned by changing the dimensions of the double trapezoidal resonator. The main high impedance line between input and output port is folded to provide more size reduction.

Figure 2. The (a) layout and (b) simulated frequency response of suppressing cell.

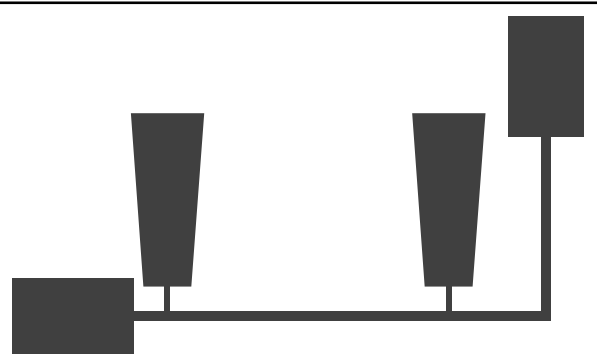

(a)

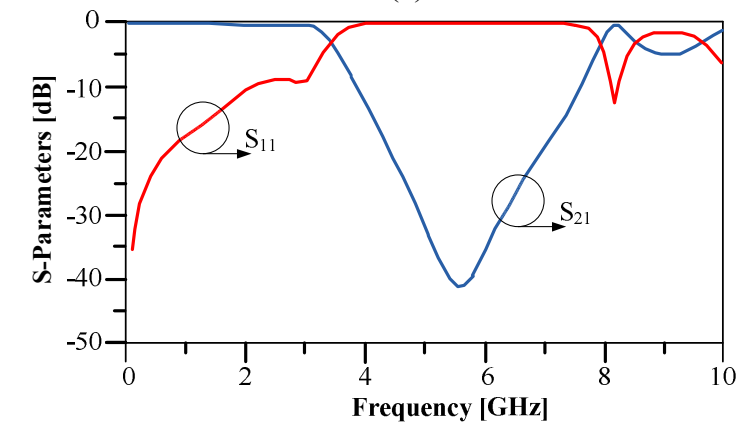

(b)

To provide a wide stop-band a suppressing cell should be added. A suppressing cell is presented as shown in Fig. 2. This suppressing cell is composed of two trapezoidal shaped open stubs. The proposed suppressing cell provides a $\mathrm{TZ}$ near $5.5 \mathrm{GHz}$ and also provides a suppression band near $4 \mathrm{GHz}$ up to $7 \mathrm{GHz}$.
Figure 3. The (a) layout and (b) simulated S-parameters of the second suppressing cell.

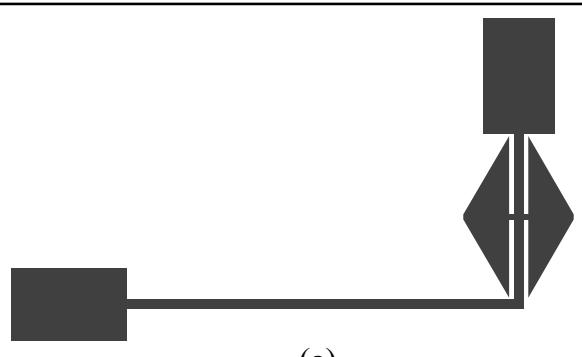

(a)

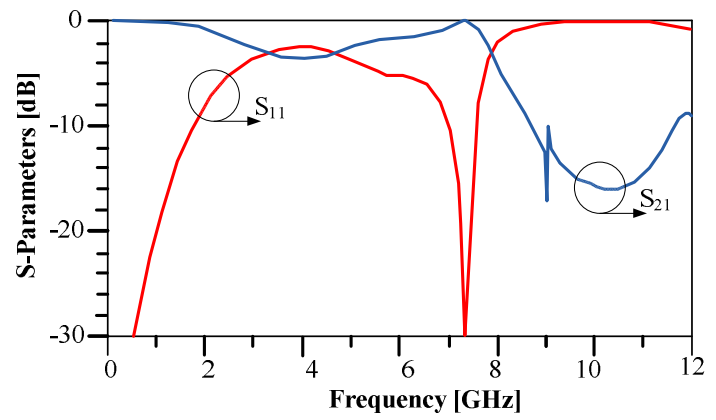

(b)

The obtained TZ by using the suppressor can widen the suppressing band of the filter.

Another suppressing cell is proposed to provide stop-band at higher frequencies. A double triangular resonator is applied to propose the second suppressing cell. The layout and S-parameters of the second suppressing cell is shown in Fig. 3. As seen, the proposed second suppressing cell provides two TZs near $4 \mathrm{GHz}$ and $10 \mathrm{GHz}$. Also, it provides a suppression band near $8.5 \mathrm{GHz}$ up to $12 \mathrm{GHz}$. The TZs obtained by the main resonator, first suppressing cell and second suppressing cell can provide a wide suppressing band for the proposed filter.

\section{RESULTS OF THE DESIGNED LPF}

By combining of the designed resonators and suppressors, the structure of the proposed LPF will be obtained. The layout of the presented LPF is illustrated in Fig. 4(a). The presented LPF dimensions are $9.7 \mathrm{~mm} \times 4.3 \mathrm{~mm}$, which is corresponding to the normalized circuit size (NCS) of $0.13 \lambda \mathrm{g} \times$ $0.058 \lambda \mathrm{g}$. The obtained dimensions show that a small size is obtained for the proposed filter. The Sparameters of the designed filter is shown in Fig. 4(b). The cut-off frequency of $3 \mathrm{GHz}$ is obtained for the designed LPF. Also, sharp transition band of $0.88 \mathrm{GHz}$ is achieved, from 3 to $3.88 \mathrm{GHz}$ with attenuations levels of $-3 \mathrm{~dB}$ and $-60 \mathrm{~dB}$, respectively. This obtained transition band results in a roll of rate equal to 65 $\mathrm{dB} / \mathrm{GHz}$. Moreover, a wide suppressing band about $6 \mathrm{GHz}$ is achieved from $3.8 \mathrm{GHz}$ up to $9.8 \mathrm{GHz}$, so, the proposed filter can highly attenuate the unwanted signals at out of the operating band frequency. Finally, the achieved figure of merit (FOM) of about 17240 is calculated for the proposed LPF, which shows a desirable FOM for the proposed filter. 
Figure 4. The (a) layout and (b) simulated frequency response of the proposed LPF.

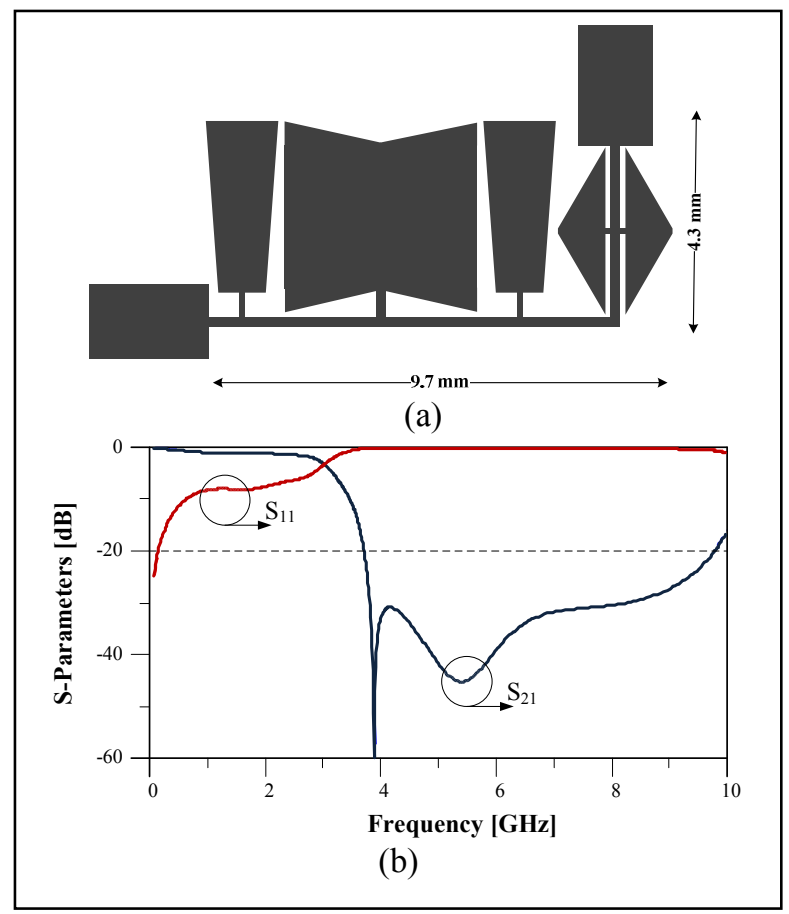

The performance comparison between of the designed filter and some similar LPFs is listed in the Table I. The results shows that the designed LPF roll of rate is very sharp $(\zeta=65)$. Also, wide stop-band with more than $20 \mathrm{~dB}$ attenuation level in stop-band $(\mathrm{SF}=20)$ is achieved. Moreover, the designed LPF has very compact size, which is smallest size in this comparsion table.

TABLE I. PERFORMANCE COMPARISON

\begin{tabular}{|c|c|c|c|c|c|c|}
\hline Refs. & $\zeta$ & RSB & SF & NCS & AF & FOM \\
\hline$[22]$ & 5.3 & 1.66 & 1.6 & $0.12 \lambda \mathrm{g} \times 0.063 \lambda \mathrm{g}$ & 1 & 1159.3 \\
\hline$[23]$ & 24 & 1.65 & 1.5 & $0.111 \lambda \mathrm{g} \times 0.091 \lambda \mathrm{g}$ & 1 & 5929 \\
\hline$[24]$ & 18 & 1.51 & 1.7 & $0.12 \lambda \mathrm{g} \times 0.071 \lambda \mathrm{g}$ & 1 & 5664 \\
\hline$[25]$ & 36 & 1.32 & 1.5 & $0.079 \lambda \mathrm{g} \times 0.079 \lambda \mathrm{g}$ & 1 & 11543 \\
\hline$[26]$ & 92 & 1.36 & 3 & $0.351 \lambda \mathrm{g} \times 0.106 \lambda \mathrm{g}$ & 1 & 10106 \\
\hline$[27]$ & 44 & 1.63 & 1 & $0.101 \lambda \mathrm{g} \times 0.15 \lambda \mathrm{g}$ & 1 & 4723 \\
\hline $\begin{array}{c}\text { This } \\
\text { work }\end{array}$ & 65 & 1.07 & 2 & $0.13 \lambda \mathrm{g} \times 0.058 \lambda \mathrm{g}$ & 1 & 17240 \\
\hline
\end{tabular}

The figure of merit (FOM) parameter, which shows the efficiency of the LPF is calculated based on eq. (1) as follows:

$$
\mathrm{FOM}=(\zeta \times \mathrm{RSB} \times \mathrm{SF}) /(\mathrm{NCS} \times \mathrm{AF})
$$

The proposed filter has the highest FOM value in this table, which shows the superiority of this device.

\section{CONCLUSION}

A compact LPF was designed in this paper. The designed LPF showed good performances, such as sharp roll off and compact size. A wide suppressing band is obtained for the designed filter, so the filter can highly attenuate the unwanted signals at out of the operating band frequency. The achieved figure of merit (FOM) about 17240 is calculated for the proposed LPF, which shows a desirable FOM for the proposed filter. With the obtained parameters the designed filter could be used in modern communications.

\section{ACKNOWLEDGMENT}

This research has been supported by the Ministry of Education, Youth and Sports of the Czech Republic under the project OP VVV Electrical Engineering Technologies with High-Level of Embedded Intelligence CZ.02.1.01/0.0/0.0/18 069/0009855.

\section{REFERENCES}

[1] M. Tahmasbi, F. Razaghian, S. Roshani, "Design of compact microstrip low pass filter using triangular and rectangular shaped resonator with ultra-wide stopband and sharp roll-off," Analog Integrated Circuits and Signal Processing. 2019 Oct 1;101(1), pp. 99-107.

[2] S. Roshani, K. Dehghani, S. Roshani, "A Lowpass Filter Design Using Curved and Fountain Shaped Resonators," Frequenz. 2019 Jul 26;73(7-8), pp. 267-272.

[3] S. Roshani, S. Roshani, A. Zarinitabar, "A modified Wilkinson power divider with ultra harmonic suppression using open stubs and lowpass filters," Analog Integrated Circuits and Signal Processing. 2019 Feb 15;98(2), pp. 395-399.

[4] A. Pirasteh, S. Roshani, S. Roshani, "Compact microstrip lowpass filter with ultrasharp response using a square-loaded modified T-shaped resonator. Turkish Journal of Electrical Engineering \& Computer Sciences," 2018 Jul 27;26(4), pp. 1736-1746.

[5] S. Roshani, "A compact microstrip low-pass filter with ultra wide stopband using compact microstrip resonant cells. International Journal of Microwave and Wireless Technologies," 2017 Jun;9(5), pp. 1023-1027.

[6] A. Kumar, M.V Kartikeya, "Design and realization of microstrip filters with new defected ground structure (DGS)," Engineering Science and Technology, an International Journal. 2017 Apr 1;20(2), pp. 679-686.

[7] M.K. Khandelwal, B.K. Kanaujia, S. Kumar, "Defected ground structure: fundamentals, analysis, and applications in modern wireless trends," International Journal of Antennas and Propagation. 2017, 2017, pp. 1-22.

[8] A. Jain, A. Goen, N.S. Dhakad, "An Overview of Elliptical Low Pass Filter by using Defected Ground Structure Method," Journal of Microwave Engineering \& Technologies. 2017; 4, pp. 13-16.

[9] M.G. Kulkarni, A.N. Cheeran, K.P. Ray, S.S. Kakatkar, "Coplanar waveguide band reject filter using electromagnetic band gap structure. Progress In Electromagnetics Research. 2017;70:53-8.

[10] P. Prakash, M.P. Abegaonkar, L. Kurra, A. Basu, S.K. Koul, "Compact Electromagnetic Bandgap (EBG) Structure with Defected Ground," IETE Journal of Research. 2016 Jan 2;62(1), pp. 120-126.

[11] S. Roshani, S. Roshani, "Design of a compact LPF and a miniaturized Wilkinson power divider using aperiodic stubs with harmonic suppression for wireless applications," Wireless Networks. 2020 Feb 1;26(2), pp. 1493-501. 
[12] M.B. Jamshidi, A. Lalbakhsh, B. Mohamadzade, H. Siahkamari, and S.M.H. Mousavi, "A novel neural-based approach for design of microstrip filters," AEU-International Journal of Electronics and Communications, 2019, 110, pp. 152847.

[13] S. Cao, Y. Han, H. Chen, J. Li, "An ultra-wide stop-band LPF using asymmetric Pi-shaped Koch fractal DGS," IEEE Access. 2017 Nov 14;5, pp. 27126-27131.

[14] N. Butt, "Performance Evaluation and Optimization of stepped impedance and stub-based low-pass filter for S-Band applications," Bahria University Journal of Information \& Communication Technologies (BUJICT). 2017 Dec 29;10(2).

[15] Kumar L, Parihar MS. Compact hexagonal shape elliptical low pass filter with wide stop band. IEEE Microwave and Wireless Components Letters. 2016 Nov 11;26(12):978-80.

[16] M.B. Jamshidi, H. Siahkamari, S. Roshani, S. Roshani, "A compact Gysel power divider design using U-shaped and Tshaped resonators with harmonics suppression," Electromagnetics. 2019 Oct 3;39(7), pp. 491-504.

[17] M. Heydari, S. Roshani, "Miniaturised unequal Wilkinson power divider using lumped component elements," Electronics Letters. 2017 Jul 5;53(16), pp. 11171119

[18] M.B. Jamshidi, A. Lalbakhsh, S. Lotfi, H. Siahkamari, B. Mohamadzade, and J. Jalilian, "A neuro based approach to designing a Wilkinson power divider", International Journal of RF and Microwave Computer Aided Engineering, 2020, 30, (3),. DOI: 10.1002/mmce.22091.

[19] M. Hookari, S. Roshani, and S. Roshani, "High efficiency balanced power amplifier using miniaturized harmonics suppressed coupler," International Journal of RF and Microwave Computer Aided Engineering, 2020, In Press, DOI: $10.1002 / \mathrm{mmce} .22252$

[20] A.R. Zirak, and S. Roshani, " A Reduced Switch Voltage Stress Class E Power Amplifier Using Harmonic Control Networks," International Journal of Advanced Computer Science and Applications, 2016, (7), pp. 38-42.

[21] A. Lalbakhsh, M.B. Jamshidi, et al. "A Compact Lowpass Filter for Satellite Communication Systems Based on Transfer Function Analysis" AEÜ - International Journal of Electronics and Communications, 2020, In press.

[22] K. Ma, K.S. Yeo, and W.M. Lim, "Ultra-wide rejection band lowpass cell," Electronics Letters, 48, (2012), pp. 99-100.

[23] J. Wang, H. Cui, and G. Zhang, "Design of compact microstrip lowpass filter with ultra-wide stopband," Electronics Letters, 48, (2012), pp. 854-856.

[24] L. Ge, J.P. Wang, Y.X. and Guo, "Compact microstrip lowpass filter with ultra-wide stopband," Electronics Letters, 46, (2010), pp. 689-691.

[25] J. Wang, et al. "Compact quasi-elliptic microstrip lowpass filter with wide stopband," Electronics Letters, 46, (2010), pp. 1384-1385.

[26] J.L. Li, S.W. Qu, and Q. Xue, "Compact microstrip lowpass filter with sharp roll-off and wide stop-band," Electronics Letters, 45, (2009), pp. 110-111.

[27] S. Luo, L. Zhu, S. Sun, "Stopband-expanded low-pass filters using microstrip coupled-line hairpin units," IEEE Microwave and Wireless Components Letters, 18, (2008), pp. 506-508. 